\title{
SERVICE PORTFOLIO AS A KEY ELEMENT OF SERVICE STRATEGY
}

\author{
WERONIKA TOSZEWSKA-CZERNIEJ
}

Koszalin University of Technology, Sciences of Economics Faculty, POLAND

e-mail: wtoszewska@gmail.com

\author{
\begin{tabular}{l|l} 
RECEIVED & 8 August 2017
\end{tabular} \\ ACCEPTED $\quad 15$ December 2017 \\ JEL \\ CLASSIFICATION \\ D15, D46, M15, 014
}

KEYWORDS service portfolio, services, service strategy, management

ABSTRACT The service strategy details how the service provider will use the service in the process of meeting the set objectives to meet the needs of the customer while achieving the direction of the company's development. Taking into account the complexity of the service process and the needs of customers is the first step in creating a service strategy. The result created services strategy is a service portfolio that properly managed is a key area of activity of the company.

The aim of this article is to present a approach based on a set of recommendations called the Information Technology Infrastructure Library (ITIL). The recommendations allows for the development of a service portfolio, which is a key element of the enterprise services strategy. The assumptions and stages of the service portfolio management process will be presented on the basis of the data characterizing the selected service market in Poland.

The process of portfolio management services allows to specify priorities and optimize the allocation of resources necessary to produce a specific service. It assumes striving to maximize the value of services, enables to know and understand the requirements for services, and select resources to maximize the effects of the service process.

\section{Introduction}

Services are a specific area of activity because of the link between the service provider and the recipient, and because of the high dependence between the service provider and the service process. Therefore, all service solutions and delivery should be driven by business needs and requirements, while reflecting the strategies and policies of the service provider organization. 
The aim of this article is to present a approach based on a set of recommendations included in Information Technology Infrastructure Library which describe the best practice in IT service management. It provides a framework for the management of IT, and focuses on the continual measurement and improvement of the quality of IT service. It takes into account both business and customer perspective. The recommendations allows for the development of a service portfolio, which is a key element of the enterprise services strategy. The article assumes that the recommendations creates the concept of service creation and expansion irrespective of the type of services being provided. Service portfolio management allows to maximize the value of services, enables to maximize the effects of the service process.

\section{Service life cycle}

In the process of creating value for the recipient, profitable service operations and the service quality are crucial. They require new mindsets and deeper insights into the nature of services, relationships, and measurement (Gummesson, 1998). Regardless of the type of service, there is a similar increase in the impact on the consumer of various social, economic and technological factors. Increasing levels of income per capita, the need for a broader range of social benefits, the size and role of the public sector, the complexity of work environments, increased specialization, the relaxation of trade barriers are recognized among the forces that drive higher consumption (Bryson, Daniels, Warf, 2004). These trends contribute worldwide to the growing importance of service activities, thus indicating the directions of strategy design activities.

The service strategy details how the service provider will use the service in the process of achieving goals, which meet the needs of the customers while achieving the directions of the company's development. The overarching source of information in the process of creating service strategies is a set of recommendations called the Information Technology Infrastructure Library (ITIL) commissioned by the UK government. ${ }^{1}$ Increasing dependence on IT services has created the need to systematize the methods and techniques used to create a set of consistent and clear guidelines for the service management process. In 2007, an enhanced and consolidated third version of ITIL was published, consisting of five core books covering the service lifecycle, together with the Official Introduction (Kuller, Grabowski, Sames, Vogt, 2010). Each from the five core publications covers up a phase of the service lifecycle from the initial definition and analysis of business requirements in ITIL Service Strategy and ITIL Service Design, through existing in the live environment within ITIL Service Transition, to conduct Service Operation and Continual Service Improvement (IT Service Management Forum, 2012). The first book applies to service strategy. It create guidance to IT service providers and their customers, to help them operate and thrive in the long term by building a clear service strategy, elements of Service Strategy actions and other ITIL books are included in Figure 1.

Taking into account the complexity of the service process and the needs of customers is the first step in creating a service strategy. It is also important to know and understand competitors operating in the market. The idea of strategic service management requires the enterprise to invest, taking into account in the development of the knowledge strategy the opinion of the employees directly involved in the service delivery process, and above all the creation of strong relationships between customers and employees (ITIL, 2007). Creating a service strategy

${ }^{1}$ ITIL was published between 1989 and 1995 by Her Majesty's Stationery Office (HMSO) in the UK on behalf of the Central Communications and Telecommunications Agency (CCTA) - now subsumed within the Office of Government Commerce (OGC). 
requires designing, drafting and implementing a procedure that takes into account client objectives, expectations, market conditions and potential.
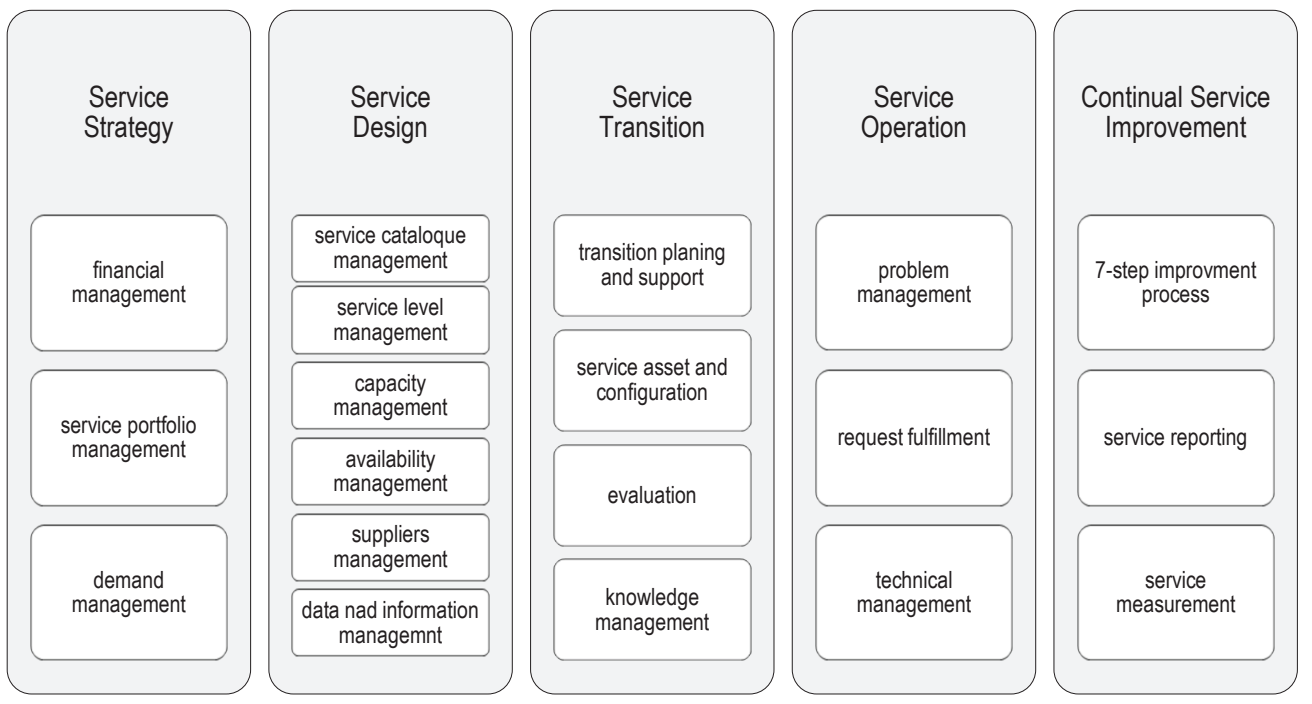

Figure 1. ITIL core books elements

Source: own elaboration based on Kuller et al. (2010), p. 26.

The service strategy provides information on how to provide services, so that they are a key area of the business. The principles on which service strategy is based are included in the service life cycle (ITIL, 2007). The first phase of the cycle includes service strategies that set rules and goals for the service life cycle (Łagowski, 2008). The formulation of ITIL service strategies is based on five basic principles:

- value creation,

- service assets,

- service provider types,

- service structures,

- service strategy fundamentals (Innotrain IT, 2013).

Creating a service strategy by any service provider should be based upon a fundamental acknowledgement that customers do not purchase products, but the satisfaction. Because of that the services provided must be perceived by the customer as a high level value outcome, which allows him to achieve his goals Introduction (Kuller et al., 2010). In the result of creating a service strategy is formed a well-managed service portfolio that is a key area of business activity.

\section{Creating service strategy}

The main aim of portfolio management is to ensure that an organization total portfolio of service is aligned with and contributing optimal value to the organization strategic objectives (ITGI IT..., 2006). Therefore, a key element 
in creating a service portfolio is to develop a strategy that addresses to the principles mentioned above. Based on the guidelines, basic actions will be presented which enable the creation of a service strategy and are crucial for a service portfolio project.

In order to create a service portfolio, it is necessary to define the pillars under which the strategy should be based on . The first pillar concerns creating value for customers. The value creation process is based on providing utility and warranty of a particular service. Utility allows the service provided to meet customer specific needs. The guarantee is an assurance or commitment of the company to fulfill specific requirements through a given service. Both of these aspects must be taken into account by the enterprise and equally fulfilled in the provision of services. Figure 2 presents the universal scheme of creating services value.

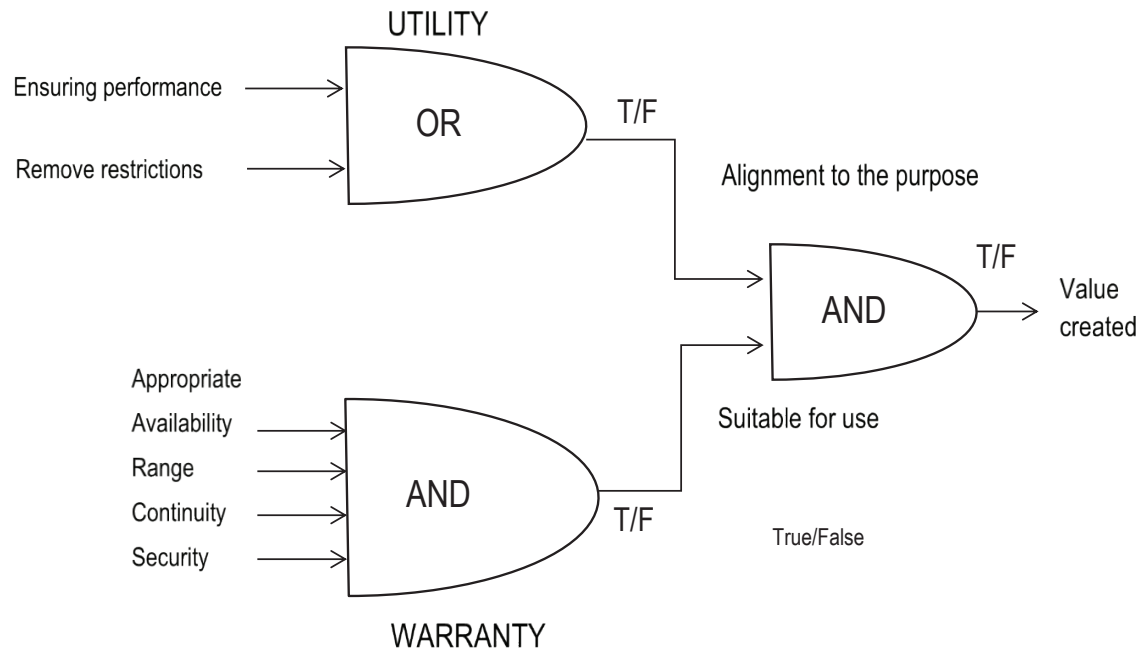

Figure 2. Service value scheme

Source: own elaboration based on ITIL Version 3 (2007); GUS, p. 18.

According to the presented scheme, the service consumer is considering the value in terms of providing utility and warranty. They determine the level of alignment of the services offered to the extent and purpose they were acquired. The company should determine what levels of usability and guarantees should be provided to create the desired level of customer service value. Bearing in mind that both aspects are indispensable, and none of them alone will produce value that will allow to effective competition on the market (ITIL, 2011).

In the process of creating value, the company uses a specific contribution that, through the transformation process, is supposed to create a service that can meet customer needs. The effectiveness of this process depends on the resources available and capabilities that have units functioning in its structure. The next step in creating a service strategy is to identify the resources needed to create the service. The ITIL concept assumes that resources and capabilities are the strategic means for every business to deliver to its customers.

The next step in developing a strategy is to determine the type of service provider. The Information Technology Infrastructure Library distinguishes two basic units involved in the service delivery process. The first one deals with 
the creation of services and in this case corresponds to the management level, who is the creator of the services offered. The second unit is a direct contractor and includes all employees who have direct contact with the customer. Depending on how the service is delivered, there are three types of providers: internal service providers, shared service units, external service providers (ITIL, 2011).

After defining the type of service provider, the next step in creating a service strategy is to define the service structure. However, this stage consists in the verification by the company of the services provided to customers by specifying:

- all participants in the service process,

- general guidelines for the implementation of the transaction,

- what is the effect of each transaction that influence on the participant,

- how can be maximize the value produced.

The result of this stage is the diagram presenting the scope of services of the company, the methods of their implementation and the entities to which they are directed.

The last step in creating a service strategy is to define a formal framework for the strategy. This is to ensure the existence of official sources that include guidelines, standards and assumptions for the strategy. They have a point of reference, based on theoretical assumptions confirming the correctness of the adopted procedure and preventing the occurrence of process or system errors. Application schema strategy development services in areas other than IT is possible and justified, since there are based on the same basic premise, namely creating value for the customer.

A properly structured service strategy determines what measures an enterprise should use to create services of desirable value to the customer. A strategic approach to service management is to create unique customer relationships based on the readiness to resolve any confusion and inconsistency in this complex process. So that it is possible to have the capacity to expand the relationship between the service provider and the receiver. An effective strategy is based on the ability to use the wealth of resources in creating the value of the service provided. Therefore the task is to create a service offering in which the resources and capabilities available will not only correspond to the present, but will be able to meet future customer needs. To achieve this, the company must create a portfolio of services that will be the right mix of services to meet business outcomes.

\section{Elements of the service portiolio}

The service portfolio describes the services provided by the company for the value they produce. Specifies customer needs and how to meet the demand. It takes into account the definition of individual services and allows to compare company offer with competitors. Service portfolio is a complete set of services that is managed by a service provider. It is used to manage the entire lifecycle of all services (IT Service Management Forum, 2012).

The service portfolio is at the heart of the decision-making process regarding the company's service offering (ITIL, 2011). The task of the service portfolio is to provide partial or complete answers to the following questions:

- Why customers should buy the services that company is offer?

- Why should customers buy services from company?

- How is the price structure for services?

- What are our strengths and weaknesses, opportunities and threats?

- How should we use our resources and capabilities? (ITIL, 2007). 
In order to implement a service portfolio as in any management process a plan should be create. Design of the service portfolio requires action in accordance with the diagram in Figure 3.

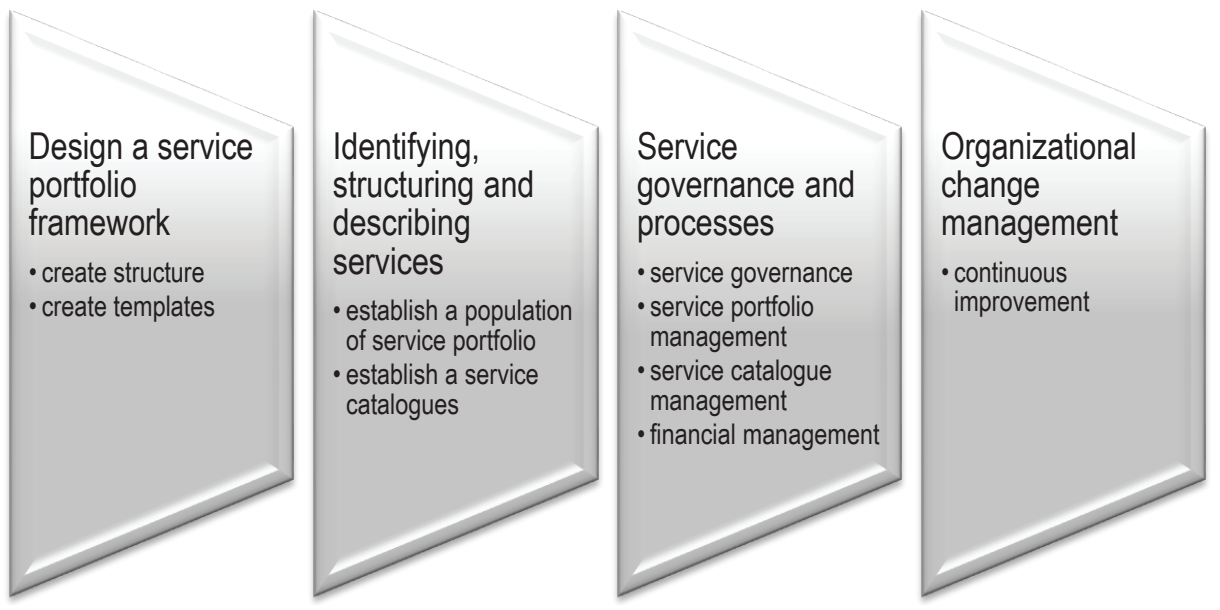

Figure 3. Stages of creating a service portfolio

Source: own elaboration based on an introductory overview of ITIL (2011), p. 4.

The portfolio consists of three categories of services. Includes services planned by the company Service Pipeline, catalog of services offered to clients Service Catalouge and services withdrawn from the offer Retired Services. Figure 4 shows the structure of the service portfolio. The categories of services included in the portfolio correspond to the lifecycle phases of the service:

- planned services are services that are planned to be launched or are in the development phase but not part of the offer available to customers,

- the catalog of services includes services currently available, placed on the market, or services ready to be placed on offer,

- retired services include all services that are no longer active.

Planned services reflect long-term service provider plans for market offerings. This service category action starts with an assessment of the market situation and customer feedback. It includes services that have been requested, which are then evaluated against the requirements that they should meet. This requires the following actions, defines and analyzes services in terms of customer requirements, cost, risk, and expected value. Based on the verification performed, a decision is made to implement or reject the service.

Approved services go to the second category of services, catalogue. It represents preparation of the supplier to provide services to customers and to a specific area of the market (ITIL, 2007). ITIL determines what conditions should be met for each placed service in the catalogue. Regardless of whether the services are active or on the market placement phase they should have:

- detailed specification,

- the characteristics of the service creation activities, 
- requisition and procurement procedures,

- SLAs (service level agreements) precisely designated service levels,

- specific support conditions,

- specified prices and return costs (Understanding ITIL..., 2008).

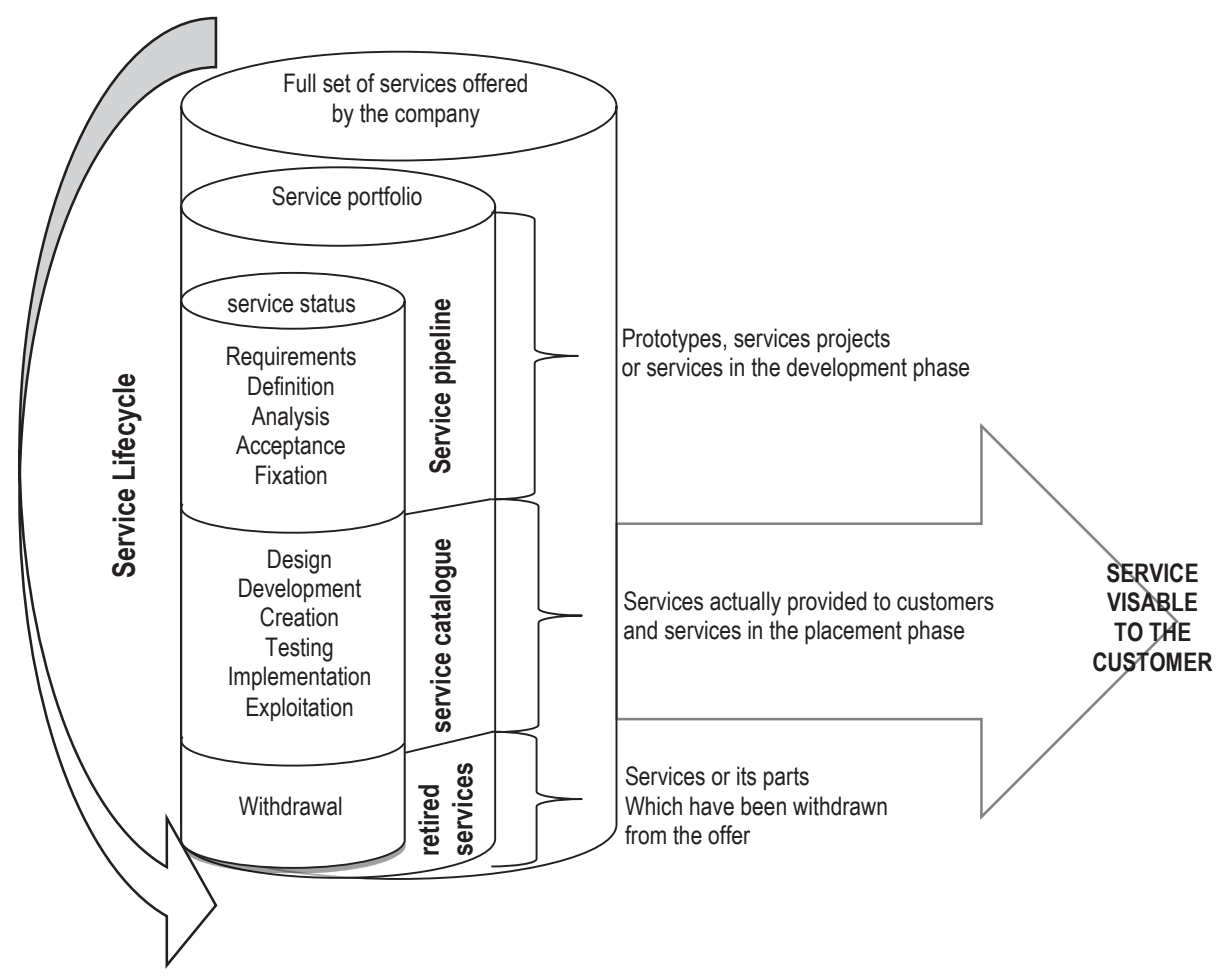

Figure 4. Elements of service lifecycle

Source: own elaboration based on ITIL (2011), p. 25.

The purpose of the catalogue is to provide solutions to customers through a particular service or group of services. Catalogue services can be configured differently, also in terms of price, so as to best meet the customer's need. This is an important tool because it reflects the actual capacity of the provider to create value for customers.

A service catalog is an area in which services are divided into components that include resources, capabilities, and processes. There are defined entry points, ways of using and supplying the service in specified resources. Therefore, the catalog may include different service listings for specific customer groups. The goal is to demonstrate the ability of the service provider to meet customer needs (ITIL, 2007).

The last category of services includes items withdrawn from the offer. It is important to execute periodic reviews of service portfolio to see if there is a service available for retraction. The category of retried service may include, non-demanded services that have been replaced by others or are no longer profitable. The main aim of 
service portfolio is to find out what consumers want, how is possible to add value to services they need (Serifovski, Christensen, 2016). These processes allows to identify and define the services that should be provided.

\section{Service portfolio in use}

In the knowledge-based economy, the developmental capacities depend more than ever on the quality of human capital, its creativity, innovative capabilities and adaptation to innovation. Recently, this quality is formulated to a decisive extent in the learning process.

Education is one of the factors affecting the socio-economic development of societies. In the process of raising the quality of human capital, not only the level of education of the society is important but also the completed education profile which determines the possibilities of a more effective functioning in the working life. Education is one of the factors determining the ability of an individual to perform a particular service. According to data from the Central Statistical Office in Poland studying a total of 1,348,822 people (GUS, 2016).

At present, globally, regionally and regionally, the gap between the needs of the dynamically changing labor market and the education and qualifications of university graduates appears to be at varying intensity. Therefore, shaping the educational offer is possible by applying an approach based on the ability of an educational service to create value, namely, it can be created on the basis of the assumptions of the service portfolio.

Polish high school graduates have the opportunity to choose a future higher education institution from among 133 public institutions, 283 non-public and 7 ecclesiastical schools. This proves the high competition of the existing educational services market. The key element in choosing a service is its ability to meet the needs of the client, so using the right service strategy makes it possible to build a suitably attractive service offering. Service management is a planned and conscious means of building and managing support structure to meet business and service objectives (A practical Guide to ITIL, 2007).

Based on the assumptions underlying the construction of the service portfolio, an example of a portfolio of educational services has been created. Figure 5 shows four basic educational services portfolio. The diagram illustrated is just an example of what classifications can be subjected to higher education and what can be included in each of the service portfolios.

The construction of the educational services portfolio requires a precise characterization of the service status for each of the portfolios. It will be possible to create portfolios that are optimally matched to current and future needs of recipients. Improving the portfolio requires the inclusion in the process of creating the service portfolio of service recipients as well as local and central units, and employers. The improvement process can take place on the basis of the seven stages used by ITIL. It assumes the following actions: developing a strategy of improvement, define a set 0 measurements, collecting the necessary data, transforms the data and the information into knowledge, present and use the information, implement improvement (IT Service Management Forum, 2012).

Figure 5 shows the components that build a portfolio for the four core groups of educational services. Each element requires a precise description that reflects the preferences of the target recipient. The example presented is merely a general scheme that needs clarification, but demonstrates that the application of ITIL recommendations may be the basis for building a portfolio of non-IT services. 


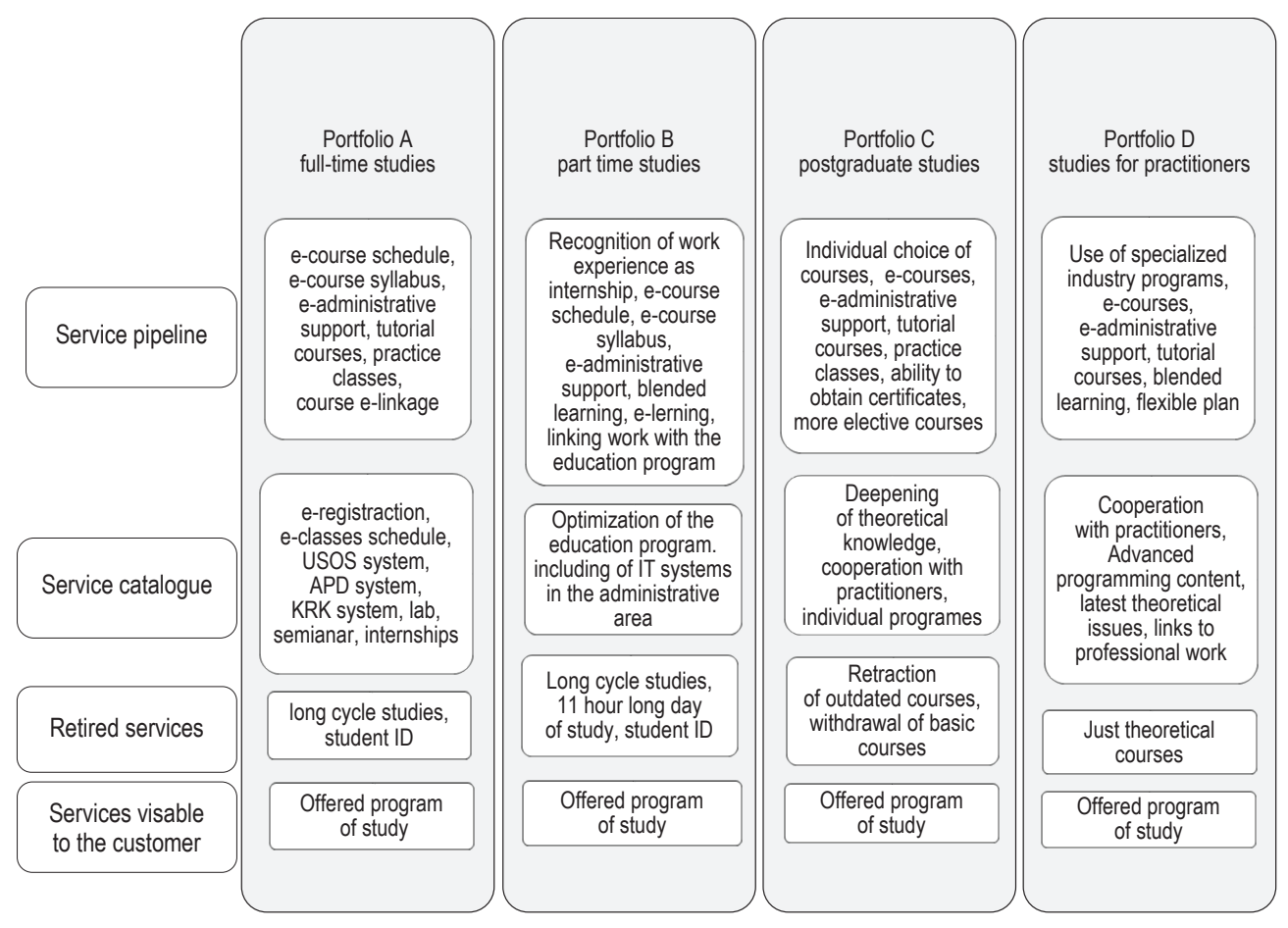

Figure 5. Educational service portfolios

Source: own elaboration.

\section{Conclusions}

A service portfolio is a tool that provides constant access to customers for desirable services that they can acquire and consume. The service portfolio is a useful tool for the efficient management of the service process. Analyzing the demand and satisfying it with an adequate service offer makes it possible to increase the efficiency of the company's operations. The portfolio of services helps in making decisions concerning the development of an offer or area of action to meet future requirements. ITIL guidelines are precise and detailed elaboration of considerable usefulness even though they are composed for the construction and development of strategies for IT services may be used for the construction of various services.

\section{Referencess}

Barclay, R. (2007). A Practical Guide to IT Service Management and ITIL v3, Part 1 - Moments of Truth. Help Desk Institute.

Bryson, J.R., Daniels, P.W., Warf, B. (2004). Service Worlds: People, Organisations, Technologies. Routledge Publishing.

Gummesson, E. (1998). Productivity, quality and relationship marketing in service operations. International Journal of Contemporary Hospitality Management, 1 (10), 4-15. Retrieved from: https://doi.org/10.1108/09596119810199282.

GUS (2016). Szkolnictwo wyższe w roku akademickim 2016/2017 dane wstępne. Retrieved from: http://stat.gov.pl/obszary tematyczne/ edukacja/edukacja/ szkolnictwo-wyzsze-w-roku-akademickim-20162017-dane-wstepne,8,4.html (4.08.2017). 
Innotrain IT (2013). Bringing It Service Management and Innovation to SMEs in Central Europe. Stuttgart.

IT Service Management Forum (2012). An introductory overview of ITIL.

ITGI IT Governance Institute (2006). Enterprise Value. Governance of IT Investments, The Val IT Framework.

ITIL (2007). Information Technology Infrastructure Library Version 3, Service Strategy. The Stationery Office

ITIL (2011). Information Technology Infrastructure Library Service Strategy. The Stationery Office.

Kuller, P., Grabowski, M., Sames, P., Vogt, M. (2010). IT Service Management Methods and Frameworks Systematization. Innovation Training IT central Europe.

Łagowski, J. (2008). ITIL v3 - Cykl życia usług IT, materiały konferencyjne z XIV Konferencji PLOUG pt. „Systemy informatyczne. Projektowanie, implementowanie, eksploatowanie".

Serifovski, N., Christensen, N.S. (2016). Building a service portfolio. Axelos Global Best Practice.

Understanding ITIL Service Portfolio Management and the Service Catalog. An approach for implementing effective service lifecycle management (2008). BMS Software. United States.

Cite this article aS: Toszewska-Czerniej, W. (2018). Service portfolio as a key element of service strategy. European Journal of Service Management, 2 (26), 283-292. DOI: 10.18276/ejsm.2018.26-35. 